УДК 004.932 DOI 10.36910/6775.24153966.2019.67.18

\title{
А.І. Поляченко
}

Київський національний університет імені Тараса Шевченка

\section{РУЧНА ОБРОБКА МЕДИЧНИХ ЗОБРАЖЕНЬ ЛІКАРЕМ-ДІАГНОСТОМ У СИСТЕМІ РОЗПІЗНАВАННЯ ТОМОГРАФІЧНИХ І РЕНТГЕНІВСЬКИХ ЗНІМКІВ ДЛЯ ПОШУКУ І ЛОКАЛІЗАЦІї ПАТОЛОГІЙ}

У статті запропоновано та побудовано систему розпізнавання томографічних і рентгенівських знімків для пошуку $і$ локалізації патологій. У даній статті необхідно розробити систему розпізнавання томографічних $i$ рентгенівських знімків для пошуку і локалізації патологій та розглянути принципи ручної обробки медичних зображсен лікарем-діагностом.

Для пошуку і локалізації аномалій на томографічних і рентгенівських знімках пропонується система, яка буде складатися з наступних блоків : блок введення інформації про пацієнта; блок обробки медичних зображень, щцо включає: згорткову нейронну мережу (ЗНМ) для класифікації томографічних і рентгенівських знімків; ЗНМ для визначення залежностей значень просторового фактора $W Z$ від стандартизованих $Z$-значень $і$ з наступним розрахунком коефіцієнту загальної просторової автокореляції; ЗНМ для сегментації томографічних $i$ рентгенівських знімків; підсистему ручної обробки медичних зображень, щчо представлена лікаремдіагностом;блок для встановлення висновку, що включає нейронну мережу (НМ), призначену для порівняння отриманих результатів; блок для класифікації виявлених патологій, щи включає НМ; базу даних, як вже існуючих знімків, так і нових, у т.ч. з результатом оброблення; блок підготовки звіту.

Ключові слова:ручна обробка, система розпізнавання, томографічні і рентгенівські знімки, пошук і локалізачія патологій, лікар-діагност.

\section{А.И. Поляченко \\ Киевский национальный университет имени Тараса Шевченко \\ РУЧНАЯ ОБРАБОТКА МЕДИЦИНСКИХ ИЗОБРАЖЕНИЙ ВРАЧА-ДИАГНОСТА В СИСТЕМЕ РАСПОЗНАВАНИЯ ТОМОГРАФИЧЕСКИХ И РЕНТГЕНОВСКИХ СНИМКОВ ДЛЯ ПОИСКА И ЛОКАЛИЗАЦИИ ПАТОЛОГИЙ}

В статье предложена и построена система распознавания томографических и рентгеновских снимков для поиска и локализации патологий. В данной статье необходимо разработать систему распознавания томографических и рентгеновских снимков для поиска и локализации патологий и рассмотреть принципы ручной обработки медицинских изображсений врачом-диагностом.

Для поиска и локализации аномалий на томографических и рентгеновских снимках предлагается система, которая будет состоять из следующих блоков: блок ввода информации о пациенте; блок обработки медицинских изображений, включая: згорткових нейронную сеть (ЗЦМ) для классификации томографических и рентгеновских снимков; ЗЦМ для определения зависимостей значений пространственного фактора Wz от стандартизированных z-значений и с последующим расчетом коэффициента общей пространственной автокорреляции;ЗЦМ для сегментации томографических и рентгеновских снимков; подсистему ручной обработки медицинских изображсений, представлена врачом-диагностом; блок для установки выводу, что включает нейронную сеть (НС), предназначенную для сравнения полученных результатов; блок для классификации выявленных патологий, включая НМ; базу данных, как уже существующих снимков, так и новых, в т.ч. с результатом обработки; блок подготовки отчета.

Ключевые слова: ручная обработка, система распознавания, томографические и рентгеновские снимки, поиск и локализация патологий, врач-диагност.

\section{A.I. Poliachenko \\ Taras Shevchenko National University of Kyiv, Kyiv, Ukraine \\ MANUAL PROCESSING OF MEDICAL IMAGES BY A DIAGNOSTICIAN IN A TOMOGRAPHIC AND X-RAY RECOGNITION SYSTEM FOR THE SEARCH AND LOCALIZATION OF PATHOLOGIES}

The research paper proposes and builds a system of recognition of tomographic and $X$-ray images for finding and localization of pathologies. In this research paper, it is necessary to develop a system of recognition of tomographic and $X$-ray images for finding and localization of pathologies and to consider the principles of manual processing of medical images by a diagnostician. To find and localize anomalies on tomographic and $X$-ray images, a system is proposed which will consist of the following units: the patient information entry unit; a medical images processing unit comprising: a convolutional neural network (CNN) for the classification of tomographic and X-ray images; CNN to determine the dependence of the values of the spatial factor $\mathrm{Wz}$ on the standardized $z$-values with further calculation of the coefficient of the total spatial autocorrelation; CNN for segmentation of tomographic and X-ray images; the manual image processing subsystem presented by the diagnostician;

An opinion unit, which includes a neural network (NN) designed to compare the results obtained; a unit for classification of detected pathologies, including $N N$; database of both existing images and new ones, including with the result of processing; report preparation unit. This system includes the following units: patient information entry, medical images processing for delivering an opinion, for classification of pathologies identified, database, report preparation. In the proposed 
system, the initial step is to obtain tomographic or X-ray images, which are then fed to the patient information entry and medical images processing units. As a result of data entry, patient information is included in the database along with tomographic or $X$-ray images. In the proposed system of recognition of tomographic and $X$-ray images, for finding and localization of pathologies it is possible for the diagnostician to highlight the area suspicious from his/her point of view and further process only this area or, using existing convolutional neural networks, identify areas of pathologies - neoplasms, or choose particular algorithms for medical images processing.

Key words: manual processing, recognition system, tomographic and X-ray images, finding and localization of pathologies, diagnostician.

Постановка проблеми. При використанні комп’ютерної та магнітно-резонансної томографії (КТ та МРТ відповідно), найважливішою із задач, що постає перед лікарями, є визначення точних меж пухлин та інших аномальних утворень у тканинах організму людини [1]. Результатом обстеження при КТ і МРТ є серія знімків, що відповідають обраним площинам сканування. На основі отриманих знімків лікар візуально визначає наявність аномальних утворень та їх межі. Проблема полягає у тому, що наявність пухлин досить просто визначити візуально у силу іх характерних структурних особливостей, у той час як визначення точних меж між здоровими та ураженими тканинами є дуже складною задачею, яку практично неможливо вирішити без виконання додаткових замірів та розрахунків [1]. Складність цієї задачі є наслідком того, що здорові та уражені тканини на знімках КТ та МРТ можуть виглядати практично однаково, у сенсі, наприклад, кольору відповідних областей, що, у свою чергу, унеможливлює використання методів візуального аналізу зображення для виявлення меж між вказаними областями $[1,2]$. Тому виникає необхідність у побудові системи розпізнавання томографічних i рентгенівських знімків для пошуку і локалізації патологій.

Аналіз останніх досліджень і публікацій. Під час аналізу конкретного медичного зображення виникає необхідність вибору алгоритму, найбільш підходящого для його сегментації $[1,3,4]$. Фактично таке завдання стоїть, перед розробниками програмних засобів для МРТобладнання, а не перед лікарями-клініцистами, які використовують методи променевої діагностики. При виборі алгоритму доводиться враховувати як властивості конкретного медичного зображення, так і особливості певного алгоритму сегментації $[1,5]$. У роботі [9] розроблено програмне забезпечення для вирішення основних завдань інформаційної підсистеми: завдань передачі інформації між підсистемами дослідження і діагностики внутрішньочерепних новоутворень, а також реєстрація пацієнта, перегляд і редагування його даних.

У той же час практично повністю відсутня автоматизована обробка розпізнавання томографічних і рентгенівських знімків для пошуку і локалізації патологій. Тому, даний напрям дослідження, на сьогодні, $є$ актуальним.

Мета статті. У даній статті необхідно розробити систему розпізнавання томографічних $\mathrm{i}$ рентгенівських знімків для пошуку і локалізації патологій та розглянути принципи ручної обробки медичних зображень лікарем-діагностом.

Основні результати дослідження. Для пошуку і локалізації аномалій на томографічних i рентгенівських знімках пропонується система, яка буде складатися 3 наступних блоків (функціональна структура пропонуємої системи приведена на рис. 1):

- блок введення інформації про пацієнта;

- блок обробки медичних зображень, що включає:

- згорткову нейронну мережу (ЗНМ) для класифікації томографічних і рентгенівських знімків;

- ЗНМ для визначення залежностей значень просторового фактора $W z$ від стандартизованих $z$-значень і з наступним розрахунком коефіцієнту загальної просторової автокореляції;

- ЗНМ для сегментації томографічних і рентгенівських знімків;

- підсистему ручної обробки медичних зображень, що представлена лікарем-діагностом;

- блок для встановлення висновку, що включає нейронну мережу (НM), призначену для порівняння отриманих результатів;

- блок для класифікації виявлених патологій, що включає НM;

- базу даних, як вже існуючих знімків, так і нових, у т.ч. з результатом оброблення;

- блок підготовки звіту. 


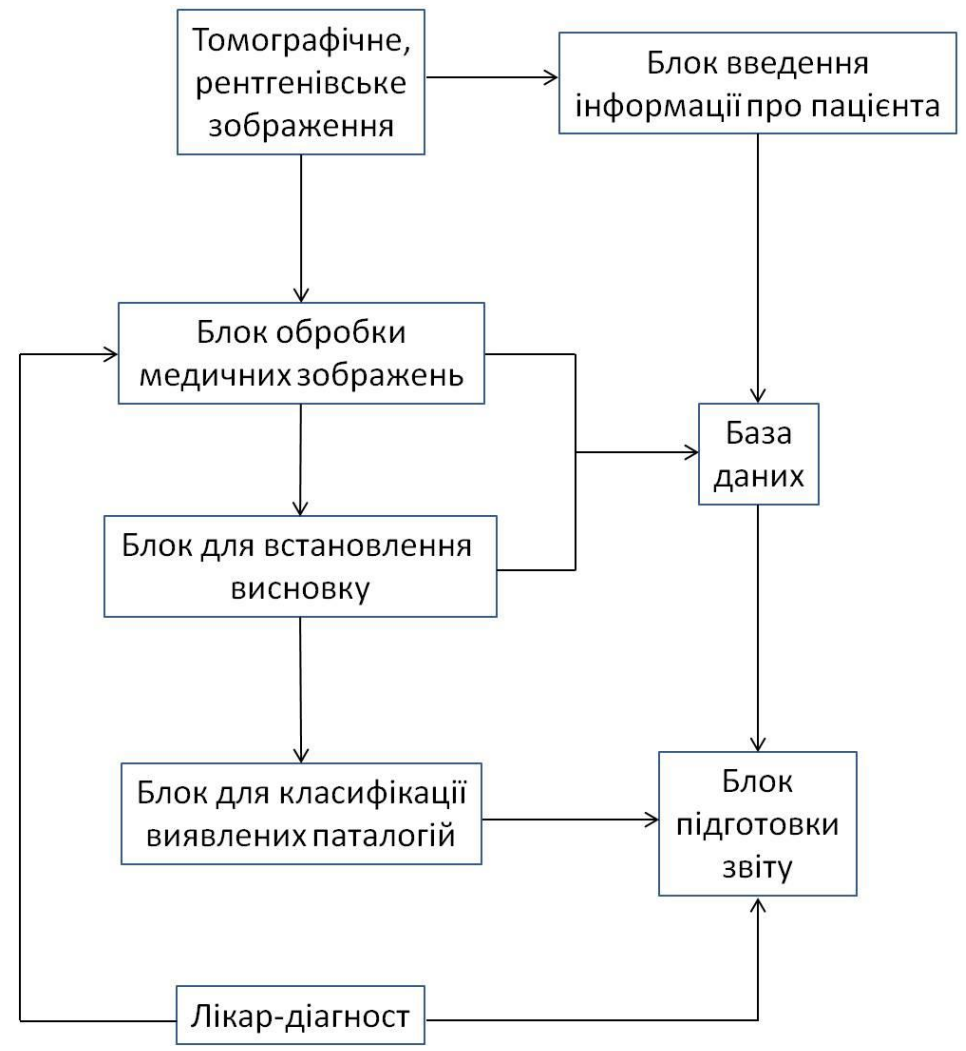

Рис. 1. Загальний вигляд функціональної структури пропонуємої системи розпізнавання томографічних і рентгенівських знімків для пошуку і локалізації патологій

У приведеній функціональній структурі пропонуємої системи (рис. 1) початковим етапом $\epsilon$ отримання томографічних чи рентгенівських знімків, які, далі, поступають до блоків введення інформації про пацієнта і обробки медичних зображень. Інформація про пацієнта в результаті введення потрапляє до бази даних разом із томографічними чи рентгенівськими знімками.

Блок обробки медичних зображень пропонуємої системи включає 4 підсистеми, які охоплюють автоматичну обробку томографічних чи рентгенівських знімків, а також обробку в ручному режимі лікарем-діагностом. У даній статті розглянуто принципи ручної обробки медичних зображень лікарем-діагностом за допомогою ЗНМ.

У пропонуємій системі розпізнавання томографічних і рентгенівських знімків для пошуку i локалізації патологій існує можливість для лікаря-діагноста самому виділяти підозрілу з його точки зору область і надалі обробити тільки цю область або за допомогою існуючих ЗНМ виділити області патологій-новоутворень, або вибрати конкретні алгоритми обробки медичних зображень.

Приклад ручної обробки медичних зображень лікарем-діагностом наведено на рис. 3.
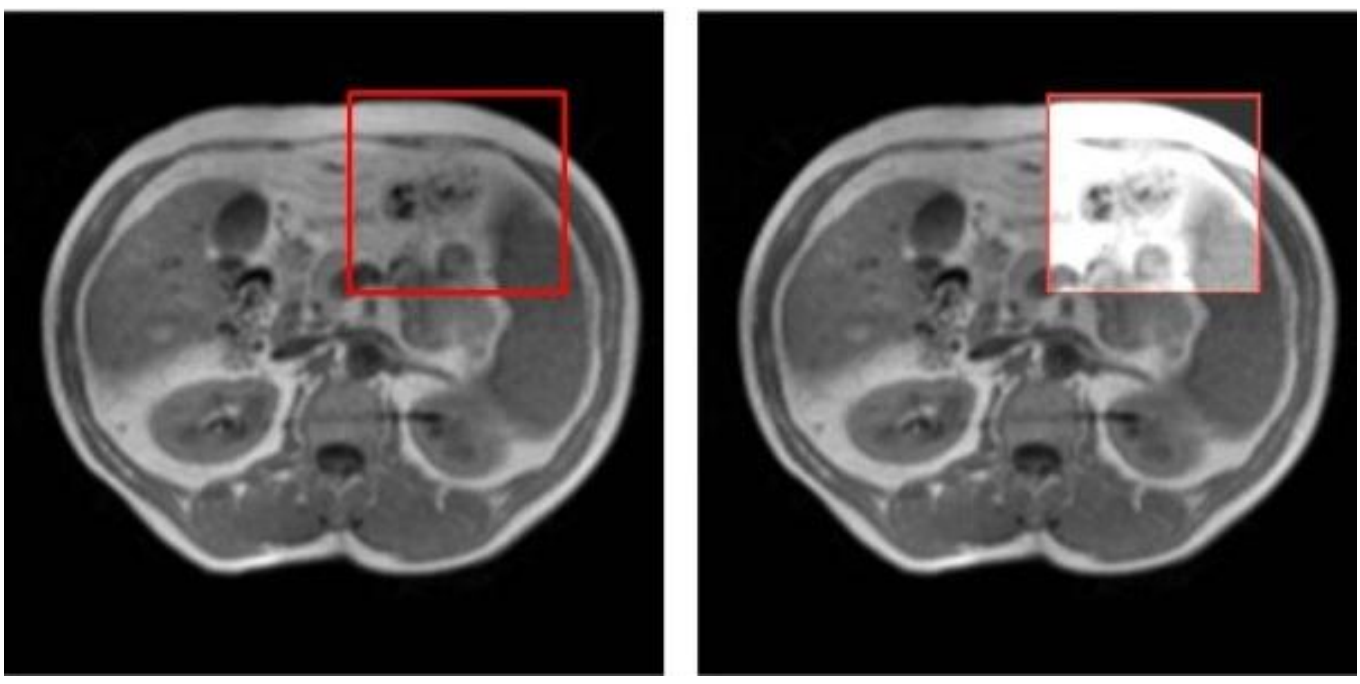


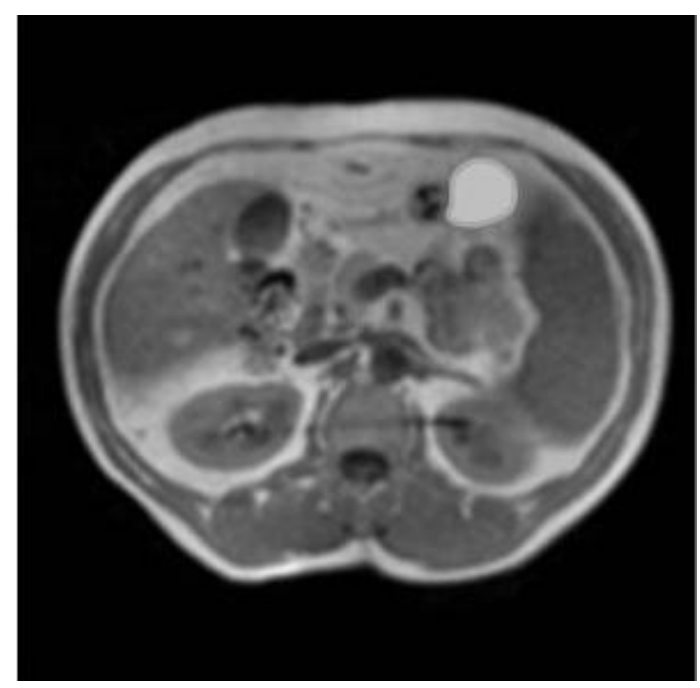

Рис. 3. Приклад ручної обробки медичних зображень лікарем-діагностом (приведено по порядку: вихідний МРТ знімок, виділення області патології, сегментація за допомогою ЗНМ)

Висновки та пропозиції. У статті запропоновано та побудовано систему розпізнавання томографічних і рентгенівських знімків для пошуку і локалізації патологій. Дана система включає блоки: введення інформації про пацієнта, обробки медичних зображень, для встановлення висновку, для класифікації виявлених патологій, базу даних, підготовки звіту. У запропонованій системі початковим етапом є отримання томографічних чи рентгенівських знімків, які, далі, поступають до блоків введення інформації про пацієнта і обробки медичних зображень. Інформація про пацієнта в результаті введення потрапляє до бази даних разом із томографічними чи рентгенівськими знімками. Блок обробки медичних зображень включає 4 підсистеми, які охоплюють автоматичну обробку томографічних чи рентгенівських знімків, а також обробку в ручному режимі лікарем-діагностом. У пропонуємій системі розпізнавання томографічних і рентгенівських знімків для пошуку і локалізації патологій існує можливість для лікаря-діагноста самому виділяти підозрілу з його точки зору область і надалі обробити тільки цю область або за допомогою існуючих ЗНМ виділити області патологій-новоутворень, або вибрати конкретні алгоритми обробки медичних зображень.

На основі розробленої системи розпізнавання томографічних і рентгенівських знімків для пошуку і локалізації патологій можна надати висновок про хворобу автоматично, або на основі суджень лікаря-діагноста.

\section{Список використаних джерел:}

1. Поляченко А.І. Можливості методів пошуку та локалізації аномалій у томографічних та рентгенівських знімках для підвищення точності встановлення діагнозу / А.І. Поляченко // Наукові нотатки. - 2018. - Вип. 64. - С. 159-165.

2. Поляченко A.I. Пошук контурів областей із певною патологічною структурою на МРТ знімках / А.І. Поляченко // Науковий журнал «Комп’ютерно-інтегровані технології: освіта, наука, виробництво». Луцьк, 2019. - Випуск № 34. - С. 96-106.

3. AnamM. An Efficient Brain Tumor Detection Algorithm Using Watershed \& Thresholding Based Segmentation / M. Anam, J. Ah, F. Tehseen // Image, Graphics and Signal Processing. - 2012. - Vol. 10. -Pp. 34-39.

4. Logeswari T. An improved implementation of brain tumor detection using segmentation based on hierarchical self organizing map / T. Logeswari, M. Kaman // International Journal of Computer Theory and Engineering. - 2010. - Vol. 2, no. 4, pp. 1793-8201.

5. Marr D. Proceedings of the Royal Society of London / D. Marr, E. Hildreth // Series B, Biological Sciences. - Vol. 207, no. 1167. - Pp. 187-217.

6. Кирсанова А.В. Автоматизированная система диагностики новообразований головного мозга по магнитно-резонансным изображениям: Дис. канд. техн. наук: 05.11.17: Санкт-Петербург, 2004. - 148 с. 